of interviews and continuing medical education 'credits' (Royal College of Physicians, 1993). Throughout, a reasonable balance should be sought between regarding the grade as mere 'marking time' and viewing it as some 'alternative' training post.

Ultimately the success of the grade will be determined by the ability of staff psychiatrists to serve their patients and colleagues well. We require skills and incentives to do both.

\section{Acknowledgements}

I thank my colleagues in the West of Scotland Staff Grade Psychiatrists' Committee for helping compile the database used in this study.

\section{References}

DEPARTMENT OF HEALTH AND SOCIAL SECURTY (1986) Hospital Medical Staffing: Achieving a Balance. London: DHSS.
- (1987) Hospital Medical Staffing: Achieving a Balance Plan for Action. London: DHSS.

Royal College of Physicians (1993) Staff Grade Doctors: Towards a Better Future. London: Royal College of Physicians.

ROYAL COLLEGE OF PSYCHIATRISTS (1995) Annual Census of Psychiatric Staffing (Occasional Paper OP34). London: Royal College of Psychiatrists.

SCOTtish COUNCIL fOR POSTGRaduate Medical and DENTA EDUCATION (1996) The educational needs of Staff Grade Doctors and Dentists in Scotland. Health Bulletin. 54. 318-331.

Standing Committee on Postgraduate Medical Education (1994) Meeting the Educational Needs of Staff Grade Doctors and Dentists. London: SCOPME.

STEIN, G. (1997) Meetings with doctors in the staff grades: the development of affiliate status. Psychiatric Bulletin. 21. 405-407.

Aileen Blower, Staff Grade Psychiatrist, Department of Child and Adolescent Psychiatry, Lomond Healthcare NHS Trust, Vale of Leven District General Hospital, Alexandria, Dunbartonshire

\title{
Sweets, newspapers and analgesics: patients' purchases from hospital shops
}

\author{
David Somerfield
}

\begin{abstract}
Aims and method The study was undertaken to examine over the counter drug sales from hospital shops. One hundred hospital shops were sent a questionnaire asking for details of drugs sold and any policy to prevent sales to patients.

Results Seventy-three shops replied, 20 of which sold medication. Most had policies which would allow sales to patients. Three shops had sold medication which was subsequently used for self-poisoning by in-patients.

Clinical implications Hospital managers and clinicians should ensure hospital shops have effective policies to prevent medication sales to patients.
\end{abstract}

Hospital shops provide an invaluable service to patients, relatives and staff. Some shops may stock drugs which are not classified as prescrip- tion only medicines and can be sold over the counter. They may sell the generic preparations of paracetamol, aspirin or ibuprofen or proprietary compound preparations containing these drugs and a variety of other substances. These are safe and well tolerated analgesics and anti-pyretics when taken at recommended dosage but in deliberate or non-deliberate overdose can create considerable morbidity and are potentially fatal. Hospitals concentrate a disproportionately high number of patients at risk of deliberate self-harm and suicide. Despite preventative measures inpatients still harm themselves. Jacobson et al (1986) showed the rate of deliberate self-harm for all psychiatric admissions over a nine-year period was $6.2 \%$. Self-mutilation was the most common method, with overdose representing over 
half the remaining cases. Precise in-patient suicide rates are unknown because the Department of Health classifies them according to place of death and over half may take place outside of the psychiatric hospital, but rates may be rising (Crammer, 1984).

Restricting the local availability of means for self-harm together with special precautions on the ward, such as close observation, is an important part of risk reduction. Morgan et al (1991) found that in many in-patient suicides special precautions failed or were not used because the degree of risk was not recognised. In these circumstances, it is important that patients are unable to purchase potentially lethal amounts of medication from the hospital shop.

\section{The study}

One hundred hospital shops were asked to complete a questionnaire giving details of any over the counter medicines sold and any policy in place governing these sales. The shops were within hospitals that were randomly selected from all hospitals identified from the current Health Service Year Book as having over 200 beds. They all had a psychiatric in-patient unit and/or general wards where patients who had harmed themselves would be treated. Shops selling medication will be sent feedback and advice based on the survey results.

\section{Findings}

Seventy-three hospital shops replied to the questionnaire of which $20(27.4 \%)$ sold medication over the counter. Thirty different types of preparation were sold. One shop alone sold 20 different types of medicine. Altogether, the 20 shops sold: 61 preparations containing paracetamol, 37 containing aspirin and four containing ibuprofen.

There were psychiatric in-patients in 15 out of the 20 hospitals whose shops sold medication and patients treated on general wards for selfharm in 17 out of 20 . Policies were in place for sales of over the counter medication in 14 out of the 20 shops. The components of policies stated by these shops are shown in Table 1 .

Eight shops commented that a restrictive sales policy was implemented because patients could use medication to harm themselves, five that it could interfere with prescribed drugs and two that the hospital management had requested restricted sales. Three hospital shops had experience of patients taking overdoses of medication bought from them. These shops still sold medication. Two of the shops subsequently sold medication in packs of four only and one only sold medicines to staff. Of the 53 shops that did
Table 1. Shops selling medication. Components of and number stating sales policies

\begin{tabular}{ll}
\hline $\begin{array}{l}\text { Medication to be kept under or behind } \\
\text { the counter }\end{array}$ & 5 \\
Ask if customer is a patient & 4 \\
Only one item per customer & 2 \\
Medication sold in four packs & 2 \\
Generic paracetamol sales to staff only & \\
(no restriction on other medication) & 2 \\
All medication sales to staff & 1 \\
Medicines only sold to staff or relative & 1 \\
\hline
\end{tabular}

not sell medication, 39 specifically prohibited sales. The Women's Royal Voluntary Service has a nationwide restriction on the sale of over the counter medication.

\section{Comment}

Over a quarter of the hospital shops surveyed sold medication which is both dangerous in overdose and can interfere with existing treatments, for instance, ibuprofen reducing the excretion of lithium. Twelve of the 20 shops selling medication were aware of these risks and had devised restrictive sales policies. Six shops had no restrictions, of which, four were in hospitals with psychiatric in-patients. Only two shops had instructions from the hospital regarding these sales. Most of the policies appeared piecemeal and could be overcome by a determined patient. The most common policy component was to put the medication behind or under the counter. There seems to be little point in doing this other than to prevent theft.

Five shops depended on identifying customers as patients which is likely to be unreliable as there may be little to distinguish a psychiatric patient from any other customer. Four shops had some or all sales restricted to staff, who could be distinguished from patients by uniform or identity badges. Only one of these restricted all medication sales to staff, while two restricted generic paracetamol, but not other paracetamol containing products and one sold to staff and relatives. The latter may be difficult to distinguish from patients.

Limiting the number of tablets to a small number per pack follows proposed Government regulations for non-pharmacy retailers, but repeat purchasing is possible and some inpatients will be particularly vulnerable to 'small' overdoses of paracetamol. These patients may sustain liver damage despite having a plasma paracetamol concentration below the standard treatment level. This may be due to the patient having taken hepatic enzymatic-inducing drugs such as anti-convulsants and alcohol (Makin et 
al, 1994) or due to depletion of hepatic glutathione resulting from repeated paracetamol overdoses or malnutrition, as in anorexia nervosa (Vale et al, 1995).

Hospital shop managers will be more used to commercial rather than clinical considerations when selling over the counter medication. Therefore, it is not surprising this study showed the danger of selling medication to hospital inpatients was not always identified and when it was, only one shop had devised what appears to be a robust restrictive sales policy. This suggests, for existing or future medication sales on hospital sites, policy should be made by the local psychiatric directorate and hospital management, not by the retailer.

Psychiatrists may want to check for themselves if the hospital shop is selling medication and if so, whether there are adequate restrictions in place to prevent sales to in-patients. The most reliable policy would be to restrict all sales of medication to staff with identification or, more simply, prohibit medication sales entirely.

\section{References}

CRAMmer, J. L. (1984) The special characteristics of suicide in hospital in-patients. British Journal of Psychiatry. 145. 460-476.

JACOBSON, R., JACKSON, M. \& BERELOWTTZ, M. (1986) Selfincineration; a controlled comparison of in-patient suicide attempts. Clinical features and history of selfharm. Psychological Medicine, 16, 107-116.

MAKIN, A. J., WENDON, J. \& WILLIAMS, R. (1994) Management of severe cases of paracetamol overdosage. Britlsh Journal of Hospital Medicine, 52, 210-213.

MORGAN, H. G. \& PRIEST, P. (1991) Suicide and other unexpected deaths among psychiatric in-patients. The Bristol confidential inquiry. British Journal of Psychiatry, 158, 368-374.

VAle, J. A. \& PROUdFoot, A. T. (1995) Paracetamol (acetaminophen) poisoning. Lancet, 346, 547-552.

David Somerfield, Senior Registrar in Rehabilitation Psychiatry, Assessment and Training, 1 Colston Fort, Montague Place, Kingsdown, Bristol BS6 5UB

\title{
Specialised in-patient psychiatric service for women
}

\author{
Dora Kohen
}

\begin{abstract}
Aims and method To describe one of the first psychiatric services in the inner-city especially designated for female psychiatric patients with severe mental illness.

Results The referral system, the staffing levels and the admission criteria have been established following needs of the patients, especially young women with perinatal problems and women from ethnic minorities. Clinical implications This single gender acute psychiatric ward has received welcome attention from mental health professionals and management at every level, and it is hoped that further discussion will help to clarify future policies and guidelines on all aspects of this venture.
\end{abstract}

In the past decade, with the better understanding of vulnerability of women in mixed gender psychiatric wards, several consumer, women and local mental health groups have initiated a discussion around the possibility of having a single gender in-patient unit for acute psychiatric admissions in City and Hackney. In 1991 the Community Health Council first expressed concern about the lack of privacy and sexual assault occurring in mixed gender psychiatric units locally (Tonks, 1992). The mental health charity MIND drew attention to growing potential for sexual assaults on women in mixed psychiatric wards. This was followed by different surveys showing that both men and women experienced sexual harassment and that the majority of women felt vulnerable in mixed wards during the acute stages of their illness. The issue was followed by discussions about segregation of women in single gender wards versus the possibility of giving the choice and offering safety to women who felt vulnerable and preferred single gender wards. 